\title{
Major adverse cardiovascular event (MACE) after percutaneous coronary intervention in one-year follow- up study
}

Hossein Farshidi ${ }^{1}$, Ahmadnoor Abdi ${ }^{2}$, Abdulhussain Madani ${ }^{3}$, Shahram Moshiri ${ }^{4}$, Abolfazl Ghasemi ${ }^{5}$, Ruhollah Hakimian $^{5}$

${ }^{1}$ M.D., Interventional Cardiologist, Associate Professor of Cardiology, Cardiovascular Research Center, Hormozgan University of Medical Sciences, Bandar Abbas, Iran

${ }^{2}$ M.D. Interventional Cardiologist, Assistant Professor of Cardiology, Cardiovascular Research Center, Hormozgan University of Medical Sciences, Bandar Abbas, Iran

${ }^{3}$ Ph.D. of Epidemiology, Associate Professor, Social Determinants in Health Promotion Research Center, Hormozgan Health Institute, Hormozgan University of Medical Sciences, Bandar Abbas, Iran

${ }^{4}$ M.D. Interventional Cardiologist, Interventional Cardiology Unit, Santa Corona General Hospital, Pietra Ligure, Italy

${ }^{5}$ M.D. Cardiovascular Research Center, Hormozgan University of Medical Sciences, Bandar Abbas, Iran

\section{Type of article: Original}

\begin{abstract}
Background: Percutaneous coronary intervention (PCI) is the most common revascularization procedure, with over 1 million performed each year, worldwide. Over the past 20 years, the increasing experience of operators coupled with the advent of newer technologies, including coronary stents and a variety of adjuvant drug therapies, have permitted more successful procedures and decreased the morbidity associated with PCIs.

Objective: To identify the incidence, predictors, and clinical implications of Major Adverse Cardiovascular Events (MACE) after PCIs.

Methods: This descriptive cross-sectional study was done in Bandar Abbas in Iran in 2015. All patients which treated with PCI in Shahid Mohammadi Hospital during a one-year period were employed. A total of 192 patients were included. At one-year follow-up in this study, incidence and predictors of MACE were evaluated in a prospective study. The data were analyzed by SPSS 19.0 and descriptive tests included frequency and percentage and mean and standard deviation. Also, Chi-square test was used for data analysis. A p value $<0.05$ was determined as significant.

Result: Of the 192 patients, $126(65.6 \%)$ were men and 66 patients were female. Stent had been implemented in $93.8 \%$ of patients. Sixty two percent of patients were treated with only one stent, two stents were deployed in $29.7 \%$ of patients and $3.6 \%$ of patients were treated with three or more stents. Of these patients, $46.9 \%$ were treated with Drug Eluted Stent (DES) and $40.1 \%$ were treated with Bare Metal Stent (BMS). Both types of stents were used in $8.3 \%$ of patients. Also, $4.7 \%$ of the patients were treated with balloon angioplasty (POBA). Angioplasty success rate was $95.3 \%$ and procedural success rate defined as achieving TIMI III flow with residual coronary stenosis under $30 \%$. No in-hospital mortality or emergency CABG was reported. Re-admission in first year after PCI was required in 34 (17.7\%) patients of which, 20 of them (10.4\%) needed target vessel revascularization (TVR). Readmission was significantly higher $(\mathrm{p}=0.034)$ in the group with BMS compared to those who had DES. MI occurred in 8 patients.

Conclusion: Our study showed the superiority of DES in comparison with BMS in decreasing readmission and less TVR, but no effect on long term mortality. We recommend more studies in this setting because patients in special groups may benefit more from DES or BMS.
\end{abstract}

Keywords: Percutaneous coronary interventions, Myocardial Infarction, Stroke

\section{Corresponding author:}

Assistant Professor Dr. Ahmadnoor Abdi. Cardiovascular Research Center, Hormozgan University of Medical Sciences, Bandar Abbas, Iran. Tel: +98.7633337379, Fax: +98.7633337192, Email: ahmadnoorabdi@gmail.com Received: May 24, 2017, Accepted: October 28, 2017, Published: February 2018

iThenticate screening: October 18, 2017, English editing: February 10, 2018, Quality control: February 14, 2018

(C) 2018 The Authors. This is an open access article under the terms of the Creative Commons Attribution-NonCommercialNoDerivs License, which permits use and distribution in any medium, provided the original work is properly cited, the use is non-commercial and no modifications or adaptations are made. 


\section{Introduction}

\subsection{Background}

Today the aggressive treatment in removing coronary artery stenosis plays an important role in the control of the patients' symptoms, and has entered a new era with the technical progress in the treatment of acute myocardial infarction (Primary PCI in ST segment Elevation MI) (1). In the course of history since the beginning of balloon angioplasty in 1977 by Doctor Gruentzig (2), we are witnessing a critical milestone.

\subsection{Statement of problem}

Today, stent deployment is the selected treatment strategy in a large number of patients with atherosclerotic coronary stenosis who have undergone PCI (1). Certainly, there is no doubt in the superiority of stenting compared to balloon angioplasty alone (3). By using stents, we could resolve coronary artery dissection, reduce the incidence of restenosis and the need for coronary artery bypass graft (CABG). On the other hand, the use of BMS was, along with restenosis, between 20 and 30\% during the first year $(4,5)$. Most of this In-stent restenosis (ISR) had led to clinical symptoms and was the cause for further invasive intervention. In order to reduce the incidence of ISR, the use of DES became popular, which largely overcame this problem, but an increase in late thrombosis in this group of stents is observed that requires longer treatment with dual antiplatelet therapy (6). Several studies have been carried out in this field that have compared the results of BMS and DES. Although reduced ISR and the need for aggressive action in using DES have reduced, most studies have shown no significant differences in mortality or myocardial infarction (MI) within the first year after PCI (7).

\subsection{Objective}

The general objective of this study was to investigate Major Adverse Cardiovascular Event (MACE) after PCI in a one-year period at Shahid Mohammadi Hospital (Bandar Abbas -Iran).

\section{Material and Methods}

\subsection{Study design and setting}

This descriptive cross-sectional study was done in 2015. Patients with PCI were studied over a one-year period at Shahid Mohammadi Hospital (Bandar Abbas in Iran).

\subsection{Data collection}

Patients' records were extracted from the hospital archive and the necessary information was transmitted to the research questionnaire and was investigated via telephone call, and the address mentioned in the patients' record. All patients were invited for an interview, and clinical status of the person including the level of physical exertion, chest pain, drug adherence and diet was evaluated. Stents used in patients over these years have included brands of Cypher (from Cordis Corporation, a Johnson \& Johnson company), Taxus TM Express 2 paclitaxel-eluting coronary stent (Boston Scientific Corporation) and Nobori (Terumo Corporation-Japan) as DES, and the brands of Skylor ${ }^{\mathrm{TM}}$ stent (Invatec, Roncadelle, Italy), Liberté stent (Boston Scientific Corp., Natick, Massachusetts) and Volo (Invatec, Italy) as BMS.

\subsection{Sample size}

Of the total of 224 patients for whom angioplasty was performed on this year, access to 32 people by phone and verbally was not possible, thus they were excluded and the study was conducted on 192 people.

\subsection{Ethical issues}

The study was approved by the Ethics Committee of Hormozgan University of Medical Sciences. The patients' information was kept confidential.

\subsection{Statistical analysis}

The data were analyzed by SPSS 19.0 software and descriptive tests including frequency and percentage and mean and standard deviation. Also, Chi-square test was used for data analysis. A p value of $<0.05$ was determined as significant.

\section{Results}

\subsection{Demographics}

Of 192 patients, there were 126 men (65.6\%) and 66 women (34.4\%), the youngest patient was 30 and the oldest was 83 years of age. The average age for all patients was 56.31 (Table 1). Descriptive information has been given in 
Table 1 considering the associated risk factors and their distribution. As shown, 53.1\% of patients were hypertensive ( $74.2 \%$ of females and $42.1 \%$ of males) followed by cigarette smoking $(27.6 \%)$ as the second more prevalent risk factors. About $65.5 \%$ of these patients had more than one significant lesion (most of them had 2 to 4 lesions with stenosis greater than $50 \%$ ). Clinical presentation was in favor of high risk patients. Seventy-one (38.5\%) patients admitted with acute MI, 30.2\% with unstable angina and 31.3\% with stable angina. In all, $13 \%$ of patients presented with acute MI received thrombolytic therapy in the emergency room ( $4.5 \%$ of females and $17.5 \%$ of males) before PCI.

Table 1. The patient frequency based on clinical variables and patient records

\begin{tabular}{|l|l|l|l|}
\hline Variables & $\mathrm{n}$ & $\%$ \\
\hline \multirow{4}{*}{ Age (years) } & $<54$ & 85 & 44.3 \\
\cline { 2 - 4 } & $54-62$ & 59 & 30.7 \\
\cline { 2 - 4 } & $63-70$ & 18 & 9.4 \\
\cline { 2 - 4 } & $>70$ & 30 & 15.6 \\
\hline \multirow{3}{*}{ Gender } & Male & 126 & 65.6 \\
\cline { 2 - 4 } & Female & 66 & 34.4 \\
\hline Positive family history of heart disease & 45 & 23.4 \\
\hline Positive history of diabetes & 44 & 22.9 \\
\hline Positive history of hypertension & 102 & 53.1 \\
\hline Positive history of dyslipidemia & 36 & 18.8 \\
\hline Positive history of MI & 57 & 29.7 \\
\hline Positive history of CHF & & 8 & 4.2 \\
\hline Positive history of CKD & Never & 16 & 8.3 \\
\hline Smoking & Current user & 127 & 66.1 \\
\cline { 2 - 4 } & Past user & 53 & 27.6 \\
\hline Previous PCI & Does not have & 12 & 6.3 \\
\cline { 2 - 4 } & Once & 742 \\
\cline { 2 - 4 } & More than once & 11 & 20.3 \\
\hline Previous CABG & Does not have & 184 & 95.8 \\
\cline { 2 - 4 } & Once & 8 & 4.2 \\
\cline { 2 - 4 } & More than once & 0 & 0 \\
\hline
\end{tabular}

\subsection{Main study results}

During procedure, there were $0.5 \%$ of coronary dissection that had been covered by stents. One case of CVA was recorded in-hospital. There was one vessel involvement in 39.1\%, two vessels in $40.1 \%$, three vessels in $20.3 \%$ and no patients with left main lesion included in this study (Table 2). Stent has been implemented in $93.8 \%$ of patients. A total of $62 \%$ of patients were treated with only one stent, two stents were deployed in $29.7 \%$ of patients and $3.6 \%$ of patients were treated with three or more stents. Of these patients, $46.9 \%$ were treated with DES and $40.1 \%$ treated with BMS. Both types of stents were used in $8.3 \%$ of patients. A total of $4.7 \%$ of the patients were treated with balloon angioplasty (POBA). Angioplasty success rate was $95.3 \%$ and procedural success rate was defined as achieving TIMI III flow with residual coronary stenosis under 30\%. No in-hospital mortality or emergency CABG were reported. Re-admission in the first year after PCI was required in 34 (17.7\%) patients of whom 20 (10.4\%) needed target vessel revascularization (TVR). Readmission was significantly higher $(\mathrm{p}=0.034)$ in the group with BMS compared to those who had DES. MI occurred in 8 patients. Patients with BMS needed higher TVR than those treated with DES (Table 2), while in each of these groups at one year, one case had a CABG. Our study did not show any significant correlation between variables and need for CABG. There was no sex preference in readmission rate. (17.5\% for males compared to $18.2 \%$ for females). Mortality occurred in four cases in the one-year follow-up, two cases were in patients treated with DES, one in BMS group and one case in patients who had been treated with both types of stents. All four patients had more than two risk factors, interestingly all were hypertensive. One of the expired patients was a smoker who continued smoking and presented with anterior MI. There was significant correlation between old age, diabetes and coronary dissection during PCI with mortality. One strong predictor for TVR was history of previous PCI ( $p=0.026$ ). Multi vessel involvement was also a predictor for readmission. 
http://www.ephysician.ir

Table 2. Frequency of the need for re-PCI, CABG at one year after PCI, based on the variables dependent to intervention

\begin{tabular}{|c|c|c|c|c|c|c|c|}
\hline \multirow{2}{*}{\multicolumn{2}{|c|}{ Variables }} & \multicolumn{2}{|c|}{$\begin{array}{l}\text { Re-PCI one year after } \\
\text { PCI; } n(\%)\end{array}$} & \multicolumn{2}{|c|}{$\begin{array}{l}\text { CABG at one year after } \\
\text { PCI; } n(\%)\end{array}$} & \multicolumn{2}{|c|}{$\mathrm{p}$-value } \\
\hline & & Yes & No & Yes & No & PCI & CABG \\
\hline \multirow{3}{*}{$\begin{array}{l}\text { The primary reason of } \\
\text { PCI }\end{array}$} & AMI & $7(3.6)$ & $67(34.9)$ & $1(0.5)$ & $73(38)$ & \multirow{3}{*}{0.913} & \multirow{3}{*}{1.000} \\
\hline & Unstable angina & $7(3.6)$ & $51(29.6)$ & $1(0.5)$ & $57(29.7)$ & & \\
\hline & Stable Angina & $6(3.1)$ & $54(28.1)$ & $1(0.5)$ & $59(30.7)$ & & \\
\hline \multirow{4}{*}{$\begin{array}{l}\text { The number of vessels } \\
\text { involved }\end{array}$} & 1 & $7(3.6)$ & $69(35.9)$ & $1(0.5)$ & $75(39.1)$ & \multirow[t]{4}{*}{0.008} & \multirow[t]{4}{*}{0.805} \\
\hline & 2 & $4(2.1)$ & $73(38)$ & $2(1)$ & $75(39.1)$ & & \\
\hline & 3 & $9(4.7)$ & $30(15.6)$ & $0(0)$ & $39(20.3)$ & & \\
\hline & Left main & $0(0)$ & $0(0)$ & $0(0)$ & $0(0)$ & & \\
\hline \multirow{3}{*}{$\begin{array}{l}\text { The number of } \\
\text { vascular lesions }\end{array}$} & 1 & $2(1)$ & $47(24.5)$ & $0(0)$ & $49(25.5)$ & \multirow[t]{3}{*}{0.563} & \multirow[t]{3}{*}{0.580} \\
\hline & 3,2, or 4 & $15(7.8)$ & $105(54.7)$ & $3(1.6)$ & $117(60.9)$ & & \\
\hline & 5 or more & $3(1.6)$ & $20(10.4)$ & $0(0)$ & $23(12)$ & & \\
\hline \multirow[t]{3}{*}{$\overline{E F}$} & $>50$ & $17(8.6)$ & $129(67.2)$ & $3(1.6)$ & $143(74.5)$ & \multirow{3}{*}{0.642} & \multirow{3}{*}{0.642} \\
\hline & 35 to 50 & $3(1.6)$ & $36(18.7)$ & $0(0)$ & $39(20.3)$ & & \\
\hline & $<35$ & $0(0)$ & $7(3.6)$ & $0(0)$ & $7(3.6)$ & & \\
\hline \multirow[t]{2}{*}{ The use of stents } & Yes & $19(9.9)$ & $161(83.9)$ & $3(1.6)$ & $177(92.2)$ & \multirow[t]{2}{*}{1.000} & \multirow[t]{2}{*}{1.000} \\
\hline & No & $1(0.5)$ & $11(5.7)$ & $1(0.5)$ & $12(6.2)$ & & \\
\hline \multirow[t]{3}{*}{ Type of stent } & drug-eluting & $7(3.6)$ & $83(43.2)$ & $1(0.5)$ & $89(46.4)$ & \multirow[t]{3}{*}{0.359} & \multirow[t]{3}{*}{0.434} \\
\hline & non-drug-eluting & $10(5.2)$ & $67(34.9)$ & $1(0.5)$ & $76(39.6)$ & & \\
\hline & $\begin{array}{l}\text { drug-eluting and } \\
\text { non-drug-eluting }\end{array}$ & $3(1.6)$ & $13(6.8)$ & $0(0)$ & $24(12.6)$ & & \\
\hline \multirow[t]{4}{*}{ The number of stents } & 0 & $0(0)$ & $9(4.7)$ & $0(0)$ & $9(4.7)$ & \multirow[t]{4}{*}{0.294} & \multirow[t]{4}{*}{0.418} \\
\hline & 1 & $12(6.3)$ & $107(55.7)$ & $1(0.5)$ & $118(61.5)$ & & \\
\hline & 2 & $6(3.1)$ & $51(29.6)$ & $2(1)$ & $55(28.6)$ & & \\
\hline & 3 or more & $2(1)$ & $5(2.6)$ & $0(0)$ & $7(3.6)$ & & \\
\hline The use of & Yes & $1(0.5)$ & $24(12.5)$ & $0(0)$ & $25(13)$ & 0.326 & 1.000 \\
\hline thrombolytic & No & $19(9.9)$ & $148(77.1)$ & $3(1.6)$ & $164(80.4)$ & & \\
\hline MI during & Yes & $1(0.5)$ & $5(2.6)$ & $1(0.5)$ & $5(2.6)$ & 1.000 & 0.091 \\
\hline hospitalization & No & $19(9.9)$ & $167(87)$ & $2(1)$ & $184(95.8)$ & & \\
\hline The number of lesions & Any & $0(0)$ & $8(4.2)$ & $1(0.5)$ & $7(3.6)$ & 0.020 & 0.116 \\
\hline resolved & Some & $16(8.3)$ & $80(41.7)$ & $1(0.5)$ & $95(49.5)$ & & \\
\hline & All & $4(2.1)$ & $84(43.8)$ & $1(0.5)$ & $87(45.3)$ & & \\
\hline The number of & 0 & $4(2.1)$ & $84(43.8)$ & $1(0.5)$ & $87(45.3)$ & 0.028 & 0.600 \\
\hline diseased vessels after & 1 & $10(5.2)$ & $65(33.9)$ & $2(1)$ & $73(38)$ & & \\
\hline PCI & 2 & $5(2.6)$ & $22(11.6)$ & $0(0)$ & $27(14.1)$ & & \\
\hline & 3 & $1(0.5)$ & $1(0.5)$ & $0(0)$ & $2(1)$ & & \\
\hline & Left main & $0(0)$ & $0(0)$ & $0(0)$ & $0(0)$ & & \\
\hline CVA during & Yes & $0(0)$ & $1(0.5)$ & $0(0)$ & $1(0.5)$ & 1.000 & 1.000 \\
\hline hospitalization & No & $20(10.4)$ & $171(89.1)$ & $3(1.6)$ & $188(97.9)$ & & \\
\hline Bleeding during PCI & Yes & $0(0)$ & $1(0.5)$ & $0(0)$ & $1(0.5)$ & 1.000 & 1.000 \\
\hline & No & $20(10.4)$ & $171(89.1)$ & $3(1.6)$ & $188(97.9)$ & & \\
\hline
\end{tabular}

\section{Discussion}

Considering Bandar Abbas and the existence of an active port and international airport and the high traffic of passengers and terminal traffic that have daily admission, over 6,000 truck and trailer drivers (8) from different Iranian cities, this lack of access was predictable. The most important finding in these patients in both groups was the early success, including the improvement in chest pain and no MACE in less than 30 days, which was a sign of successful PCI (9). The patients for whom DES had been used, required less hospitalization than BMS patients $(5.7 \%$ vs. $8.6 \%)$, which was statistically significant $(\mathrm{p}=0.034)$. Several studies showed that BMS implementation was associated with more MACE in one-year follow-up $(10,11)$. In different studies, lack of referring and late 
referring to treatment centers are observed. This finding, or findings of various studies which is useful to reduce readmissions in the first year after angioplasty, is consistent $(12,13)$. High incidence of restenosis with BMS resulted in more re-admission and TVR lead to reduced BMS use, and especially in developed countries, DES implementation been increased on the previous years. Now BMS is used in about $10-30 \%$ of angioplasty cases (14). In some hospitals more than $80 \%$ of used stents are DES. BMS has been restricted to people who are not capable of long-term dual antiplatelet using artery diameter over $4 \mathrm{~mm}$ or patients who have planned surgery and patients with short life expectancy $(15,16)$. BMS has been restricted to people who are not capable of long-term dual antiplatelet using artery diameter over $4 \mathrm{~mm}$ or patients who have planned surgery and patients with short life expectancy (15, 16). S.E. Kassaian and colleagues at Tehran Heart Center, showed that deployment of the BMS in comparison with the first- and second-generation DES in primary PCI were the strongest predictors of 12-month MACE (17). In our study, 38.5\% of patients had MI and a number of them had undergone Primary PCI, which could be potentially high risk for MACE in future. Studies about one-year mortality in a setting of acute and primary PCI, demonstrated higher mortality rate and there was no difference in TVR between DES and BMS. A study conducted by Khosravi and colleagues in Isfahan, demonstrated $1 \%$ mortality in a group of patients of whom $85 \%$ had unstable angina (18) and in comparison with catheterization laboratories of low experience, our data is acceptable. Lateness in seeking help for angina and presenting to the emergency room in our city is another problem that results in late treatment and facing MI and related complication (19). What is clear from studies, is high mortality after PCI in patients with MI (20). In this study, mortality rate has no significant relationship with the type of stent as shown by Tina L. and colleagues (21), although several studies have been reported for long-term stent thrombosis (6). One of the patients with anterior wall MI presented to hospital with LAD late stent thrombosis. This case has not had regular drug use, especially clopidogrel. Several studies point to the late stent thrombosis in most cases, due to lack of proper use of dual antiplatelet $(4,22)$. Although with new stent generation and far-reaching changes that have been created in the production of stents, it is expected to face less stent thrombosis in future and moreover, reduce stent thrombosis in the future. In this study used stents were Cyper and Taxus that had already replaced by third generation stents with advice of 6 months of antiplatelet therapy which is a good news for future of PCI. One of the strong predictors for TVR was history of previous PCI and multi vessel involvement. We recommend that to overcome this issue, treatment strategies must be built on full revascularization and effective risk factors control.

\section{Conclusions}

Our study showed the superiority of DES in comparison with BMS in decreasing readmission and less TVR, but no effect on long term mortality. There are very strong predictors for MI like hypertension, previous MI, primary PCI and coronary dissection. Predictors for death as shown in our study, were old age, diabetes, and coronary dissection. Our study showed the superiority of DES in comparison with BMS in decreasing readmission and less TVR, but no effect on long term mortality. We recommend more studies in this setting because patients in special groups may benefit more from DES or BMS.

\section{Acknowledgments:}

This study was supported by Hormozgan University of Medical Sciences. We thank the deputy of research and Catheterization laboratory staff for their help.

\section{Conflict of Interest:}

There is no conflict of interest to be declared.

\section{Authors' contributions:}

All authors contributed to this project and article equally. All authors read and approved the final manuscript.

\section{References:}

1) Montalescot G, Ongen Z, Guindy R, Sousa A, Lu SZ, Pahlajani D, et al. Predictors of outcome in patients undergoing PCI. Results of the RIVIERA study. Int J Cardiol. 2008; 129(3): 379-87. doi: 10.1016/j.ijcard.2007.07.127. PMID: 18055032.

2) Gruntzig AR, Senning A, Siegenthaler WE. Nonoperative dilatation of coronary-artery stenosis: percutaneous transluminal coronary angioplasty. N Engl J Med. 1979; 301(2): 61-8. 10.1056/NEJM197907123010201. PMID: 449946.

3) Fischman DL, Leon MB, Baim DS, Schatz RA, Savage MP, Penn I, et al. A randomized comparison of coronary-stent placement and balloon angioplasty in the treatment of coronary artery disease. Stent 
Restenosis Study Investigators. N Engl J Med. 1994; 331(8): 496-501. doi: 10.1056/NEJM199408253310802. PMID: 8041414.

4) Caixeta A, Leon MB, Lansky AJ, Nikolsky E, Aoki J, Moses JW, et al. 5-year clinical outcomes after sirolimus-eluting stent implantation insights from a patient-level pooled analysis of 4 randomized trials comparing sirolimus-eluting stents with bare-metal stents. J Am Coll Cardiol. 2009; 54(10): 894-902. doi: 10.1016/j.jacc.2009.04.077. PMID: 19712798.

5) Yeh RW, Normand SL, Wolf RE, Jones PG, Ho KK, Cohen DJ, et al. Predicting the restenosis benefit of drug-eluting versus bare metal stents in percutaneous coronary intervention. Circulation. 2011; 124(14): 1557-64. doi: 10.1161/CIRCULATIONAHA.111.045229. PMID: 21900079.

6) Daemen J, Wenaweser P, Tsuchida K, Abrecht L, Vaina S, Morger C, et al. Early and late coronary stent thrombosis of sirolimus-eluting and paclitaxel-eluting stents in routine clinical practice: data from a large two-institutional cohort study. Lancet. 2007; 369(9562): 667-78. doi: 10.1016/S0140-6736(07)60314-6. PMID: 17321312.

7) Lagerqvist B, James SK, Stenestrand U, Lindback J, Nilsson T, Wallentin L, et al. Long-term outcomes with drug-eluting stents versus bare-metal stents in Sweden. N Engl J Med. 2007; 356(10): 1009-19. doi: 10.1056/NEJMoa067722. PMID: 17296822.

8) Farshidi H, Zarenezhad M, Zare Sh, Mousavi SA, Mozafari SA. Coronary Artery Disease Risk Factors in Truck Drivers, Bandar Abbas, Iran (2009-2010). Journal of Rafsanjan University of Medical Sciences. 2013; 12(3): 195-204.

9) Kirtane AJ, Gupta A, Iyengar S, Moses JW, Leon MB, Applegate R, et al. Safety and efficacy of drugeluting and bare metal stents: comprehensive meta-analysis of randomized trials and observational studies. Circulation. 2009; 119(25): 3198-206. doi: 10.1161/CIRCULATIONAHA.108.826479. PMID: 19528338.

10) MacKenzie TA, Malenka DJ, Olmstead EM, Piper WD, Langner C, Ross CS, et al. Prediction of survival after coronary revascularization: modeling short-term, mid-term, and long-term survival. Ann Thorac Surg. 2009; 87(2): 463-72. doi: 10.1016/j.athoracsur.2008.09.042. PMID: 19161761.

11) Qureshi MA, Safian RD, Grines CL, Goldstein JA, Westveer DC, Glazier S, et al. Simplified scoring system for predicting mortality after percutaneous coronary intervention. J Am Coll Cardiol. 2003; 42(11): 1890-5. doi: 10.1067/mhj.2002.125505. PMID: 14662247.

12) Holubkov R, Laskey WK, Haviland A, Slater JC, Bourassa MG, Vlachos HA, et al. Angina 1 year after percutaneous coronary intervention: a report from the NHLBI Dynamic Registry. Am Heart J. 2002; 144(5): 826-33. PMID: 12422151.

13) Stone GW, Lansky AJ, Pocock SJ, Gersh BJ, Dangas G, Wong SC, et al. Paclitaxel-eluting stents versus bare-metal stents in acute myocardial infarction. N Engl J Med. 2009; 360(19): 1946-59. doi: 10.1056/NEJMoa0810116. PMID: 19420364.

14) Kastrati A, Mehilli J, Dirschinger J, Dotzer F, Schuhlen H, Neumann FJ, et al. Intracoronary stenting and angiographic results: strut thickness effect on restenosis outcome (ISAR-STEREO) trial. Circulation. 2001; 103(23): 2816-21. PMID: 11401938.

15) Boden WE, O'Rourke RA, Teo KK, Hartigan PM, Maron DJ, Kostuk WJ, et al. Optimal medical therapy with or without PCI for stable coronary disease. N Engl J Med. 2007; 356(15): 1503-16. 10.1056/NEJMoa070829. PMID: 17387127.

16) Mehta SR, Cannon CP, Fox KA, Wallentin L, Boden WE, Spacek R, et al. Routine vs selective invasive strategies in patients with acute coronary syndromes: a collaborative meta-analysis of randomized trials. JAMA. 2005; 293(23): 2908-17. doi: 10.1001/jama.293.23.2908. PMID: 15956636.

17) Kassaian SE, Saroukhani S, Alaeddini F, Salarifar M, Capodanno D, Poorhoseini H, et al. A Risk-Scoring Model to Predict One-year Major Adverse Cardiac Events after Percutaneous Coronary Intervention. J Tehran Heart Cent. 2015; 10(4): 167-75. PMID: 26985204, PMCID: PMC4791644.

18) Khosravi A, Pourmoghaddas M, Asadi K, Abdi A, Gholamrezaei A. Immediate results and six-month outcomes after percutaneous coronary intervention in a referral heart center in Isfahan, Iran. ARYA Atheroscler. 2011; 7(1): 24-30. PMID: 22577441, PMCID: PMC3347842.

19) Farshidi H, Rahimi S, Abdi A, Salehi S, Madani A. Factors Associated With Pre-hospital Delay in Patients With Acute Myocardial Infarction. Iran Red Crescent Med J. 2013; 15(4): 312-6. doi: 10.5812/ircmj.2367. PMID: 24083004, PMCID: PMC3785905.

20) Shishehbor MH, Amini R, Oliveria LP, Singh IM, Kelly P, Bhatt DL, et al. Comparison of drug-eluting stents versus bare-metal stents for treating ST-segment elevation myocardial infarction. JACC Cardiovasc Interv. 2008; 1(3): 227-32. doi: 10.1016/j.jcin.2008.03.011. PMID: 19463304. 
21) Slottow TL, Steinberg DH, Roy P, Javaid A, Buch AN, Okabe T, et al. Drug-eluting stents are associated with similar cardiovascular outcomes when compared to bare metal stents in the setting of acute myocardial infarction. Cardiovasc Revasc Med. 2008; 9(1): 24-8. doi: 10.1016/j.carrev.2007.06.002. PMID: 18206634.

22) Stettler C, Wandel S, Allemann S, Kastrati A, Morice MC, Schomig A, et al. Outcomes associated with drug-eluting and bare-metal stents: a collaborative network meta-analysis. Lancet. 2007; 370(9591): 93748. doi: 10.1016/S0140-6736(07)61444-5. PMID: 17869634. 